\title{
Sequential assessment of the intrahepatic expression of epidermal growth factor and transforming growth factor- $\$ 1$ in hepatofibrogenesis of a rat cirrhosis model
}

\author{
SHIGEKI KURIYAMA ${ }^{1}$, FUMI YOKOYAMA ${ }^{1}$, HIDEYUKI INOUE $^{1}$, JITSUKO TAKANO $^{1}$, MUTSUMI OGAWA $^{1}$, \\ YUKO KITA $^{1}$, HITOSHI YOSHIJI ${ }^{2}$, AKIHIRO DEGUCHI ${ }^{1}$, YASUHIKO KIMURA ${ }^{1}$, TAKASHI HIMOTO ${ }^{1}$, \\ HIROHITO YONEYAMA ${ }^{1}$, KAZUTAKA KUROKOHCHI ${ }^{1}$, TSUTOMU MASAKI ${ }^{1}$, \\ NAOHITO UCHIDA ${ }^{1}$ and SEISHIRO WATANABE ${ }^{1}$ \\ ${ }^{1}$ Department of Gastroenterology and Neurology, Kagawa University School of Medicine, 1750-1 Ikenobe, \\ Miki-cho, Kita-gun, Kagawa 761-0793; ${ }^{2}$ Third Department of Internal Medicine, \\ Nara Medical University, 840 Shijo-cho, Kashihara, Nara 634-8522, Japan
}

Received October 3, 2006; Accepted November 14, 2006

\begin{abstract}
Responses of the liver to chronic injury include inflammation, regeneration and fibrosis, which finally lead to cirrhosis. The cause of liver cirrhosis appears to be impaired proliferative capability of hepatocytes caused by continuous hepatic damage, and subsequent accumulation of extracellular matrix produced by hepatic stellate cells (HSCs). Epidermal growth factor (EGF) and transforming growth factor- $\beta 1$ (TGF-B1) play a crucial role in hepatocyte proliferation and hepatofibrogenesis, respectively. However, sequential analyses of the intrahepatic expression of EGF and TGF- $B 1$ in the course of cirrhosis development have not been examined fully. In the present study, liver cirrhosis was produced in rats by intraperitoneal administration of dimethylnitrosamine (DMN), and intrahepatic mRNA expression levels of proliferating cell nuclear antigen (PCNA), EGF and TGF-B1 were quantitatively estimated by a real-time reverse transcription-polymerase chain reaction method. Histological and semiquantitative densitometric examination of liver sections revealed that the accumulation of extracellular matrix components was increased according to the period of DMN treatment. Histological examination of liver sections of rats treated with DMN for 4 and 6 weeks revealed pre-cirrhosis and cirrhosis, respectively. Intrahepatic mRNA expression levels of PCNA and EGF correlated well. Expression levels of both molecules were increased significantly during the course of cirrhosis development, but decreased significantly at the time of
\end{abstract}

Correspondence to: Dr Shigeki Kuriyama, Department of Gastroenterology and Neurology, Kagawa University School of Medicine, 1750-1 Ikenobe, Miki-cho, Kita-gun, Kagawa 761-0793, Japan

E-mail: skuriyam@med.kagawa-u.ac.jp

Key words: liver cirrhosis, epidermal growth factor, transforming growth factor- $\beta 1$, real-time reverse transcription-polymerase chain reaction, fibrosis complete cirrhosis manifestation. In contrast, intrahepatic TGF-31 expression was increased significantly according to the period of DMN treatment, and reached a peak at the time of cirrhosis manifestation. These results suggest that proliferative capability of hepatocytes was impaired by continuous liver damage due, in part, to the decrease of a hepatocyte mitogen EGF, and that increased intrahepatic TGF- 31 activated HSCs to retrieve space lost by hepatocyte destruction, resulting in complete cirrhosis manifestation.

\section{Introduction}

Many different types of injury, such as chronic hepatitis, ethanol, biliary tract disease, iron overload and copper overload, lead to hepatocyte destruction and ultimately to hepatic fibrosis and cirrhosis. The end stage of liver fibrosis, cirrhosis, is a major public health problem worldwide owing to lifethreatening complications of portal hypertension and liver failure and to the risk of incident hepatocellular carcinoma (HCC).

Liver cirrhosis is a pathologically defined entity which is associated with a spectrum of characteristic clinical manifestations. The cardinal pathological features reflect irreversible chronic injury of the hepatic parenchyma and include extensive fibrosis in association with the formation of regenerative nodules. These features result from hepatocyte necrosis, collapse of the supporting reticulin network with subsequent connective tissue deposition, distortion of the vascular bed, and nodular regeneration of remaining liver parenchyma. Among them, important causes of cirrhosis appear to be impaired proliferative capability of hepatocytes caused by continuous or recurrent hepatic damage, and subsequent collagen fiber deposition caused by activated hepatic stellate cells (HSCs). Therefore, it is an important issue to examine the mechanisms of impaired proliferative capability of hepatocytes and HSC activation.

We previously showed that G1 phase-related cell cycle molecules, the adaptor molecule Shc and the myristoylated 
alanine-rich $\mathrm{C}$ kinase substrate play important roles in proliferation of both hepatocytes and HCC cells (1-8). Furthermore, we demonstrated that the intrahepatic expression of hepatocyte growth factor and its specific receptor c-Met was decreased in hepatofibrogenesis of a rat cirrhosis model (9). In the present study, to learn more about the mechanism of hepatofibrogenesis, we sequentially examined the intrahepatic expression of epidermal growth factor (EGF) and transforming growth factor- $\beta 1$ (TGF- $\beta 1$ ) in the course of cirrhosis development, using a rat cirrhosis model.

EGF is a low-molecular-weight polypeptide of approximately $6 \mathrm{kDa}$ that binds to the same receptor as TGF- $\alpha$, the EGF-receptor (10-12). It has been shown that EGF was able to bind with 4-8 times higher affinity to the receptor than TGF- $\alpha$ (13). EGF is known as a potent mitogen for several cell types including hepatocytes (14-16). Synthesis of EGF occurs primarily in the salivary and Brunner's glands. EGF is stored in granules and secreted into the gut, and to a lesser extent into the blood stream. It has been shown that periportal hepatocytes took up more than $90 \%$ of the EGF in the first pass (17). It has been shown that EGF expression was increased immediately after partial hepatectomy in normal rats (18). However, changes of intrahepatic EGF expression in hepatofibrogenesis remain to be studied.

Cytokines regulating the inflammatory response to injury modulate hepatic fibrogenesis both in vitro and in vivo (19). Among a variety of growth factors, TGF- $\beta 1$ appears to be a key mediator in human fibrogenesis (20). TGF- $\beta 1$ is produced in a paracrine manner by Kupffer cells, sinusoidal endothelial cells, bile duct epithelial cells, hepatocytes, or HSCs themselves $(21,22)$. TGF- 31 production by HSCs is important, and thus points to this cytokine as a classic autocrine factor $(21,22)$. Although TGF- $\beta 1$ is believed to play a critical role in hepatofibrogenesis, sequential changes of intrahepatic TGF- 1 expression have not been examined fully.

Repeated intraperitoneal administration of dimethylnitrosamine (DMN) to rats has been shown to cause liver cirrhosis, characterized by hepatocellular necrosis, increased connective tissue and formation of regenerative nodules (23-25). Therefore, in the present study, we produced a rat cirrhosis model by administering DMN intraperitoneally and sequentially assessed intrahepatic mRNA expression levels of EGF and TGF- 31 in the rat cirrhosis model.

\section{Materials and methods}

Animals and chemical treatment. Six-week-old male SpragueDawley rats were purchased from Japan SLC (Hamamatsu, Japan). Animals were kept under a specific pathogen-free condition at $24 \pm 2^{\circ} \mathrm{C}$ and in a 12-h day/night light cycle with food and water available ad libitum throughout the experimental period. Animal experiments were performed with the approved protocols and in accordance with the institutional recommendations for the proper care and use of laboratory animals.

Chemicals were purchased from Sigma Chemical Co. (St. Louis, MO, USA) or Wako Pure Chemical Co. (Osaka, Japan), unless otherwise mentioned. To develop cirrhosis in rat liver, $1 \%$ DMN dissolved in phosphate-buffered saline (PBS) was given intraperitoneally at $1 \mathrm{ml}$ per kg body weight for 3 consecutive days per week. Two, 4 and 6 weeks after the initiation of DMN treatment, livers were isolated and perfused, as described previously (26). Briefly, rats were anesthetized with ether and the abdomen was opened. The portal vein was cannulated and approximately $5 \mathrm{ml}$ of a blood sample was collected from each animal. The liver was then cleared of blood with perfusion of $50 \mathrm{ml}$ of PBS from the portal vein and removed for histological and mRNA expression analyses. Untreated 8-week-old rats were also sacrificed as normal controls. Sera were obtained from the whole blood samples by centrifugation to examine biochemical parameters of DMN-treated and untreated animals. Each group consisted of 5 animals.

Histological analysis. For histological analysis, approximately half the volume of the left-lateral hepatic lobe from each animal was fixed in $10 \%$ neutral-buffered formalin, embedded in paraffin and sliced into $4-\mu \mathrm{m}$-thick sections. For examining liver damage, sections were stained with hematoxylin-eosin, and for evaluating the degree of liver fibrosis, sections were subjected to Azan-Mallory staining. Semiquantitative analysis of fibrosis development was carried out, using a computerassisted Olympus microscope system (BX51 and DP70; Olympus, Tokyo, Japan) and the public domain software Image J. Six ocular fields (x100 magnification) per specimen were selected randomly for evaluating the ratios of fibrosis areas in liver sections.

RNA extraction and reverse transcription $(R T)$. Total RNA was extracted from approximately $30 \mathrm{mg}$ of liver tissues, using the RNeasy Protect Mini Kit (Qiagen; Hilden, Germany) according to the manufacturer's instructions. Complementary DNA (cDNA) was synthesized in a $30-\mu 1$ reaction volume. A sample of total RNA $(2 \mu \mathrm{g})$ was incubated at $65^{\circ} \mathrm{C}$ for $10 \mathrm{~min}$, and then cooled for $2 \mathrm{~min}$ on ice. A sample was transferred to the tube of the Ready-To-Go You-Prime First-Strand Beads (Amersham Biosciences; Piscataway, NJ, USA) and incubated for $1 \mathrm{~min}$ at room temperature with the oligo-dT primers (Invitrogen; Carlsbad, CA, USA). The reaction was then incubated at $37^{\circ} \mathrm{C}$ for $60 \mathrm{~min}$. The obtained cDNA was used for quantitative real-time polymerase chain reaction (PCR).

Quantitative real-time PCR. Quantitative PCR was performed by the real-time PCR system, LightCycler (Roche Diagnostics; Mannheim, Germany), using the SYBR Green I double strand DNA binding dye (Roche Diagnostics). The amplification of a target with the primers listed in Table I was carried out in a total volume of $20 \mu \mathrm{l}$ containing $0.3 \mu \mathrm{M}$ of each primer, $3 \mathrm{mM}$ $\mathrm{MgCl}_{2}, 2 \mu \mathrm{l}$ of the master mixture (LightCycler FastStrand DNA Master SYBR Green I) and $1 \mu 1$ of template cDNA. The reaction mixture was preheated at $95^{\circ} \mathrm{C}$ for $10 \mathrm{~min}$, followed by 40 cycles at $95^{\circ} \mathrm{C}$ for $10 \mathrm{sec}, 62^{\circ} \mathrm{C}$ for $10 \mathrm{sec}$ and $72^{\circ} \mathrm{C}$ for $7 \mathrm{sec}$. Fluorescence data were collected after each extension step. Melting curve analysis was performed by heating the PCR product at $95^{\circ} \mathrm{C}$, then cooling to $65^{\circ} \mathrm{C}$ and finally raising to $95^{\circ} \mathrm{C}$ with a $0.1^{\circ} \mathrm{C} / \mathrm{sec}$ temperature transition rate while continuously monitoring the fluorescence. Fluorescence was analyzed by using the LightCycler Software version 3.5 (Roche Diagnostics). The crossing point for each reaction was determined and manual baseline adjustment. To quantify 
Table I. Primers used for real-time PCR.

\begin{tabular}{lc}
\hline Gene & \multicolumn{2}{c}{ Primers } \\
\hline GAPDH & For: 5'-TGAACGGGAAGCTCACTGG-3' \\
& Rev: 5'-TCCACCACCCTGTTGCTGTA-3' \\
PCNA & For: 5'-AAAGAAGAGGAAGCTGTGTC-3' \\
& Rev: 5'-CTTTAAGTGTCCCATGTCAG-3' \\
& For: 5'-CTTAGGGATGTGGGGGACTT-3' \\
& Rev: 5'-TTGGGCTGTTGGTGTTCCTC-3' \\
TGF-ß1 & For: 5'-ATGACATGAACCGACCCTTC-3' \\
& Rev: 5'-TGTGTTGGTTGTAGAGGGCA-3' \\
\hline
\end{tabular}

For, forward; Rev, reverse.

and prove the integrity of isolated RNA, real-time RT-PCR analysis for glyceraldehyde-3-phosphate dehydrogenase (GAPDH) was also carried out. Each run consisted of GAPDH as an internal standard and a negative control without samples.
Statistical analysis. All values are expressed as means \pm SD. All analyses were performed using the computer-assisted StatView program (SAS Institute, Gary, NC, USA). Standard descriptive statistics, Student's t-test and Welch t-test, were used according to the distribution of experimental values. A $\mathrm{p}$-value of $<0.05$ was considered to indicate a significant difference between groups.

\section{Results}

Development of liver cirrhosis in rats treated with DMN. Intraperitoneal administration of DMN to rats is known to cause liver cirrhosis, characterized by hepatocellular necrosis, increased connective tissue and formation of regenerative nodules. To evaluate the amount of collagen fibers in the liver, liver sections collected from DMN-treated and untreated rats were stained with Azan-Mallory dyes. There were almost no fibers in the liver of untreated normal controls (Fig. 1A). Fine collagen fibers were observed only at periportal regions, known as Rappaport's zone 1, in the liver of rats treated with DMN for 2 weeks (Fig. 1B). Azan-Mallory staining of liver sections of rats treated with DMN for 4 weeks revealed that the fibrotic septa became apparent although they were still relatively thin and predominantly restricted to zone 1 (Fig. 1C). This state was considered to be pre-cirrhotic. Azan-Mallory staining of liver sections of rats treated with DMN for 6 weeks
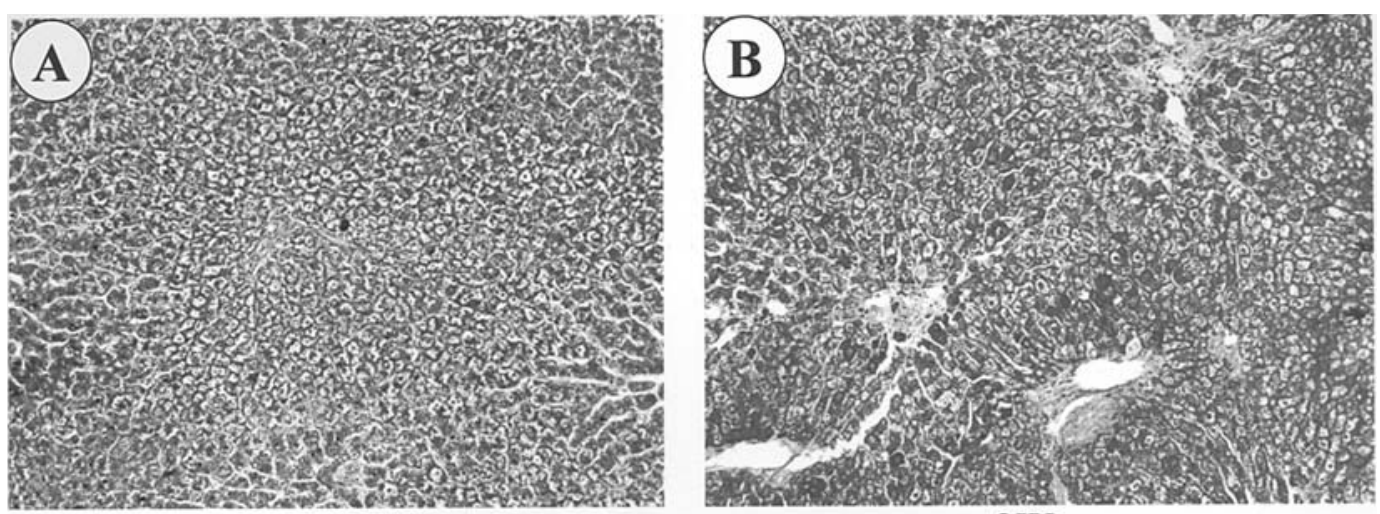

normal

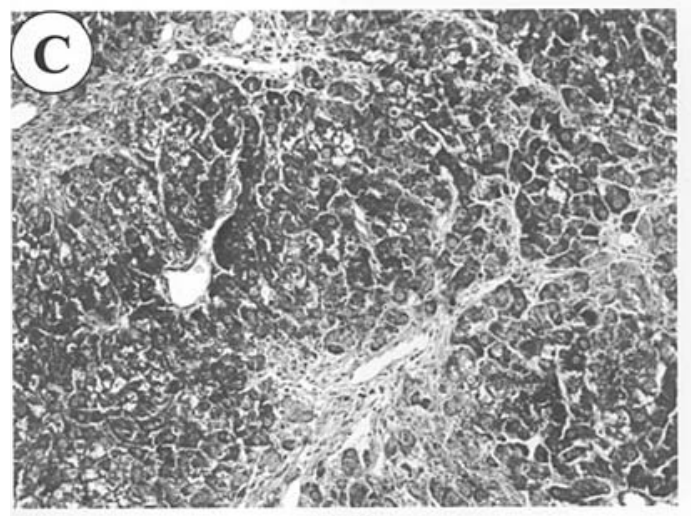

$4 \mathrm{~W}$
2W

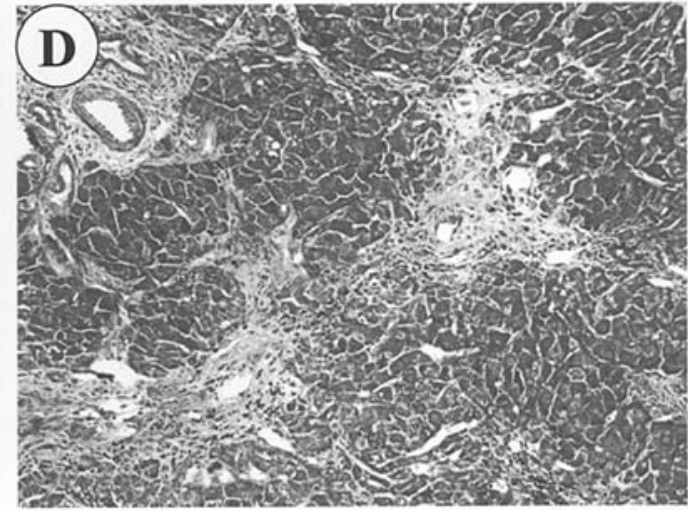

6W

Figure 1. Azan-Mallory staining of liver sections of rats treated with DMN. There were almost no fibers in the liver of untreated normal controls (A). Fine collagen fibers were observed only at periportal regions in the liver of rats treated with DMN for 2 weeks (B). Azan-Mallory staining of the liver of rats treated with DMN for 4 weeks revealed that the fibrotic septa were relatively thin and predominantly restricted to periportal regions (C). Azan-Mallory staining of sections from the liver after 6-week DMN treatment revealed that cirrhosis was completely manifested by increase and thickening of the fibrotic septa, traversing the lobular parenchyma by porto-venous or porto-portal bridging, thus promoting the formation of pseudolobuli (D). Representative pictures are shown in the figure. Original magnification $\mathrm{x} 100$ 


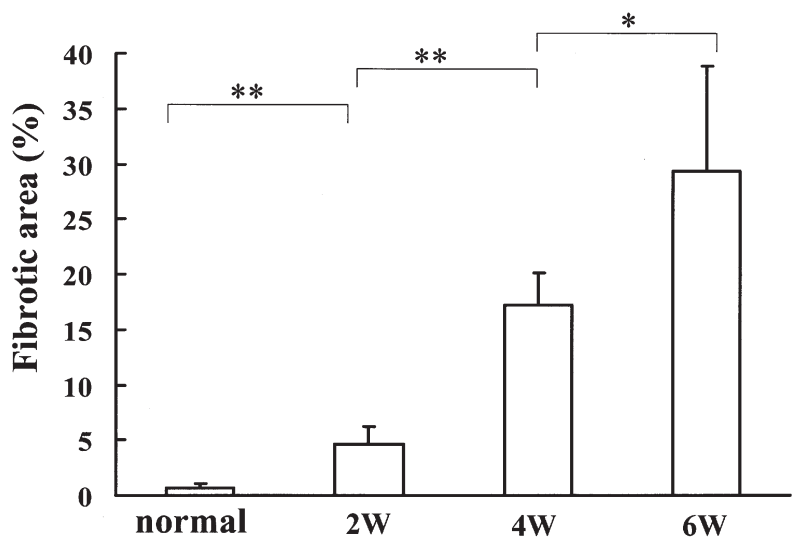

Figure 2. Semiquantitative evaluation of extracellular matrix amounts in the liver. Liver sections of rats treated intraperitoneally with DMN for 2, 4 and 6 weeks were stained with Azan-Mallory dyes. Liver sections of DMNuntreated rat were also examined as normal controls. Accumulated amounts of extracellular matrix were assessed semiquantitatively by a densitometric analysis. Extracellular matrix in the liver was significantly increased according to the period of DMN treatment. Each bar represents the mean \pm SD of 5 animals. ${ }^{*} 0.01<\mathrm{p}<0.05 ;{ }^{* *} 0.001<\mathrm{p}<0.01$.

revealed that cirrhosis was completely manifested by increase and thickening of the fibrotic septa, traversing the lobular parenchyma by porto-venous or porto-portal bridging, thus promoting the formation of pseudolobuli (Fig. 1D).

Semiquantitative evaluation of collagen fibers accumulated in the liver of rats treated with DMN. We then semiquantitatively evaluated the amounts of collagen fibers accumulated in the liver of rats treated with DMN. As shown Fig. 2, fibrosis areas in the liver were enlarged significantly according to the period of DMN treatment. Fibrosis areas in the liver of rats treated with DMN for 2 weeks were significantly larger than those of normal controls. Hepatic fibrosis areas of rats treated with DMN for 4 weeks were significantly larger than those of rats treated with DMN for 2 weeks. Fibrosis areas in the liver of rats treated with DMN for 6 weeks were further enlarged and significantly larger than those of 4-week-treated animals.

Serum levels of liver-related biochemical parameters in rats treated with DMN. To evaluate the degree of hepatocyte destruction and changes of hepatic reserve during the course of cirrhosis development, blood samples were collected from the portal vein of rats when they were sacrificed. Serum values of liver-related biochemical parameters, asparate aminotransferase (AST) and alanine aminotransferase (ALT), which reflect the degree of hepatocyte destruction, and albumin and total bilirubin, which reflect hepatic reserve, were determined. Serum values of AST (Fig. 3A) and ALT (Fig. 3B) were elevated gradually according to the period of DMN treatment. Serum AST values of animals treated with DMN for 6 weeks were significantly higher than those of both normal, and 2and 4-week-treated ones. Serum ALT values of animals treated with DMN for 6 weeks were significantly higher than those of normal and 2-week-treated ones. These results indicate that hepatocyte destruction was not only continuous but also enhanced during the course of cirrhosis development.

Serum values of albumin were decreased gradually according to the period of DMN treatment. The values of
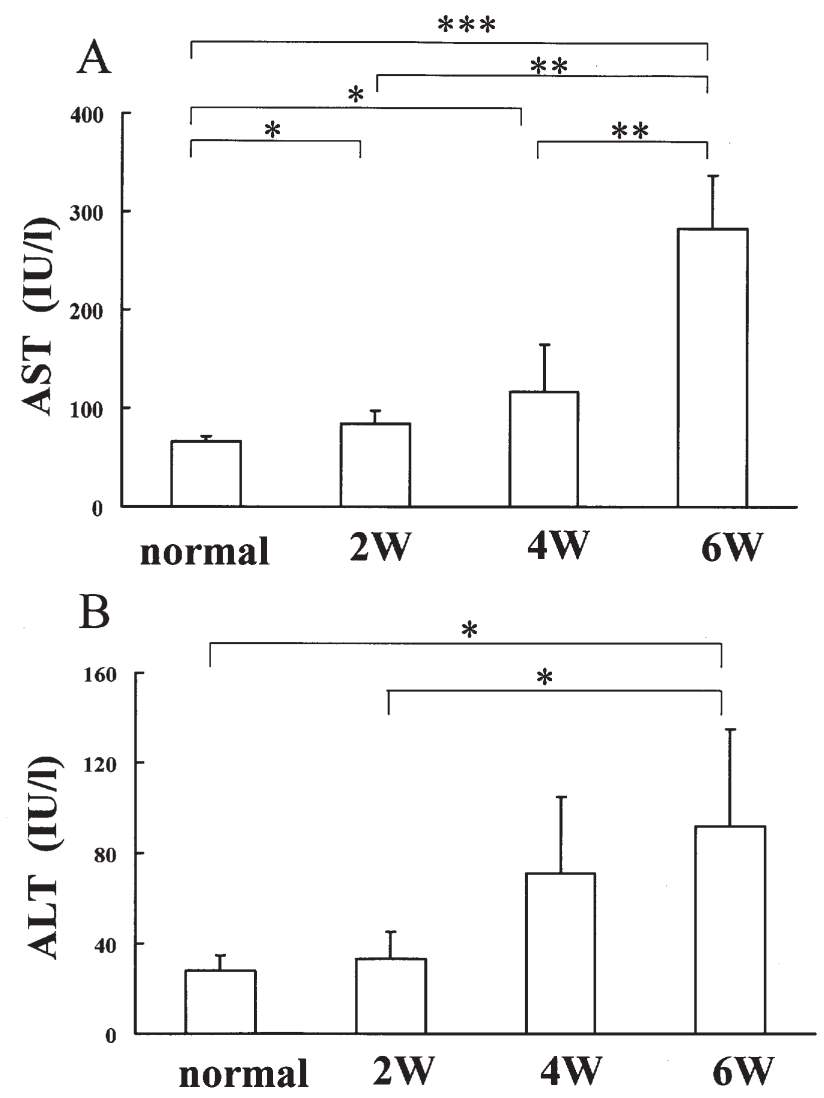

Figure 3. Serum levels of biochemical parameters reflecting hepatocyte destruction in rats treated with DMN. To examine the degree of hepatocyte destruction during the course of cirrhosis development in DMN-treated rats, blood samples were collected from the portal vein when animals were sacrificed. Serum values of AST (A) and ALT (B), which are released from destructed hepatocytes, were elevated gradually according to the period of DMN treatment. Serum AST values of animals treated with DMN for 6 weeks were significantly higher than those of both normal, and 2- and 4-weektreated ones. Serum ALT values of animals treated with DMN for 6 weeks were significantly higher than those of normal and 2-week-treated ones. Each bar represents the mean $\pm \mathrm{SD}$ of 5 animals. ${ }^{*} 0.01<\mathrm{p}<0.05 ;{ }^{* *} 0.001<\mathrm{p}<0.01$; ${ }^{* * * *} \mathrm{p}<0.001$.

animals treated with DMN for 4 weeks were significantly lower than those of normal controls. Serum values of albumin were markedly decreased thereafter, and the values of animals treated with DMN for 6 weeks were significantly lower than those of both normal, and 2- and 4-week-treated ones (Fig. 4A). Serum values of total bilirubin were increased gradually according to the period of DMN treatment, and the values of animals treated with DMN for 6 weeks were significantly higher than those of both normal, and 2- and 4-week-treated ones (Fig. 4B). Furthermore, although no animals died before 4-week DMN treatment, more than half of the animals died between 4- and 6-week DMN treatment. Taken collectively, these results indicate that hepatic reverse was significantly decreased according to the period of DMN treatment and severely impaired at the time of complete cirrhosis manifestation.

Intrahepatic expression of PCNA during the course of cirrhosis development. To examine the proliferating capability of hepatocytes during the development of liver cirrhosis, total RNA was extracted from the liver of rats treated with DMN and intrahepatic mRNA levels of PCNA were quantitatively 


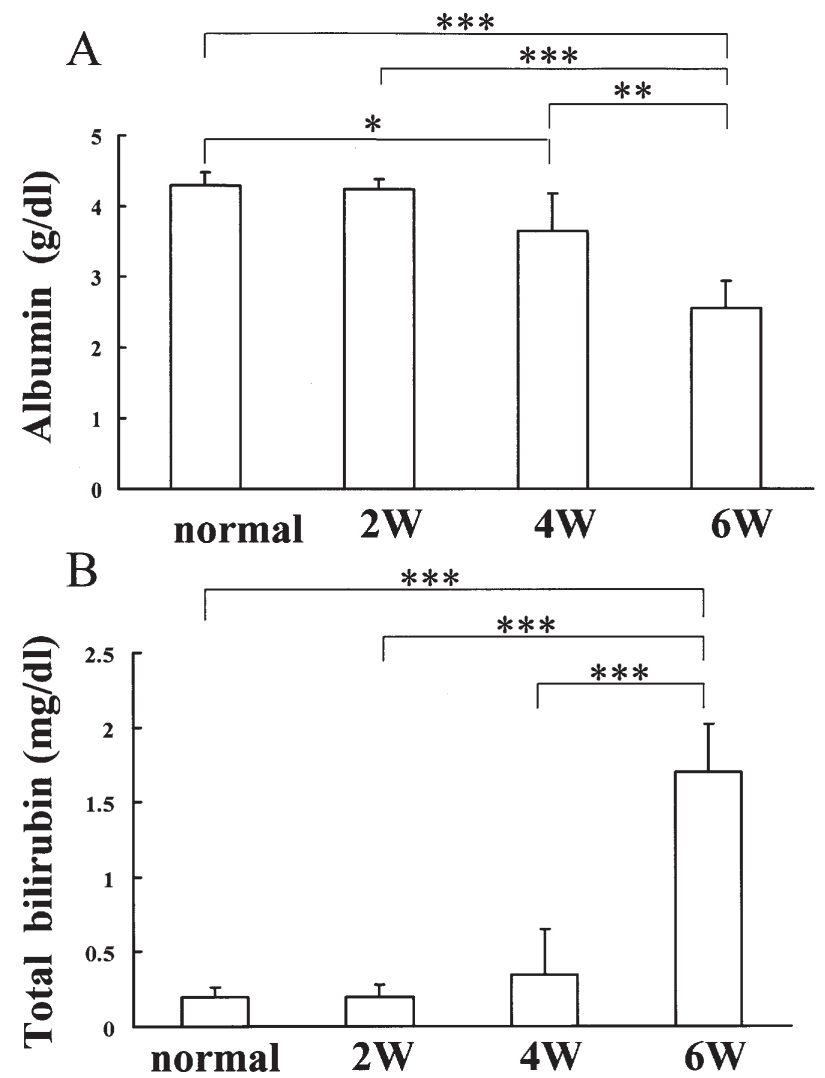

Figure 4. Serum levels of biochemical parameters reflecting hepatic reserve in rats treated with DMN. To examine the changes of hepatic reserve during the course of cirrhosis development in DMN-treated rats, blood samples were collected from the portal vein when animals were sacrificed, and serum values of albumin (A) and total bilirubin (B), which reflect hepatic reserve, were determined. Serum values of albumin were decreased gradually according to the period of DMN treatment, and the values of animals treated with DMN for 6 weeks were significantly lower than those of both normal, and 2- and 4-week-treated ones. Serum values of total bilirubin were increased gradually according to the period of DMN treatment, and the values of animals treated with DMN for 6 weeks were significantly higher than those of both normal, and 2 - and 4-week-treated ones. Each bar represents the mean \pm SD of 5 animals. ${ }^{*} 0.01<\mathrm{p}<0.05 ;{ }^{* *} 0.001<\mathrm{p}<0.01 ;{ }^{* * *} \mathrm{p}<0.001$.

evaluated by a real-time RT-PCR method. PCNA expression in the liver was increased according to the period of DMN treatment (Fig. 5). Intrahepatic mRNA levels of PCNA of rats treated with DMN for 2 weeks were significantly higher than those of normal controls. Intrahepatic PCNA expression was further increased in rats treated with DMN for 4 weeks, with a significant difference compared with 2-week-treated rats. However, intrahepatic PCNA expression in rats treated with DMN for 6 weeks was decreased significantly compared with that in rats treated with DMN for 4 weeks. Intrahepatic mRNA levels of PCNA were not significantly different between normal and 6-week DMN-treated animals.

Intrahepatic expression of EGF during the course of cirrhosis development. To examine intrahepatic expression levels of EGF during the course of cirrhosis development, total RNA was extracted from the liver of rats treated with DMN and mRNA levels were quantitatively evaluated by a real-time RT-PCR method. EGF expression in the liver was increased according to the period of DMN treatment (Fig. 6). Intrahepatic mRNA levels of EGF of rats treated with DMN for 4 weeks

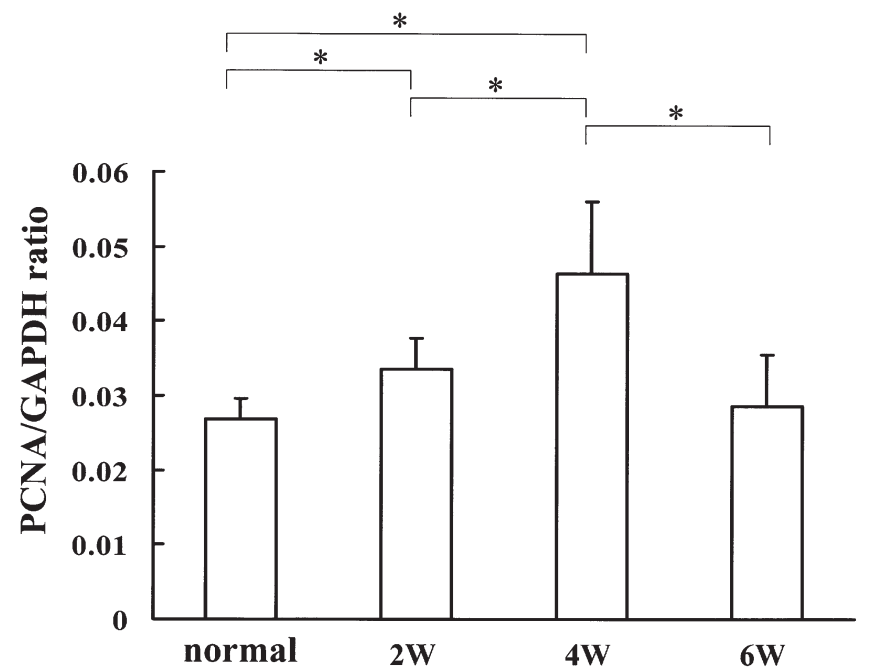

Figure 5. Intrahepatic mRNA levels of PCNA in the course of cirrhosis development. To quantitatively estimate PCNA mRNA expression in the liver during the course of cirrhosis development, a real-time RT-PCR method was employed. The value of each amplified message was standardized by the amount of GAPDH quantified from the same sample. Intrahepatic mRNA levels of PCNA were increased significantly until 4-week DMN treatment. However, they were then decreased significantly in rat treated with DMN for 6 weeks, compared with animals treated with DMN for 4 weeks. Each bar represents the mean \pm SD of 5 animals. ${ }^{*} 0.01<\mathrm{p}<0.05$.

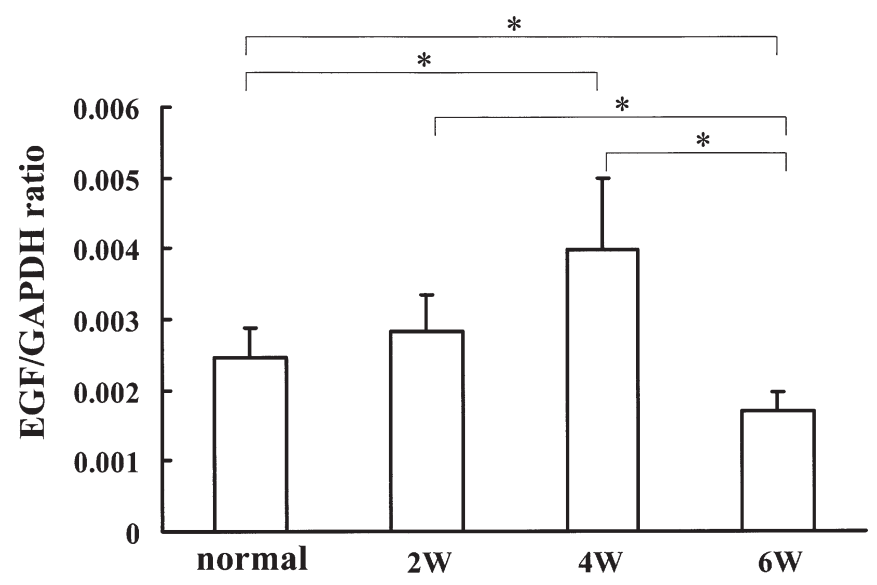

Figure 6. Intrahepatic mRNA levels of EGF in the course of cirrhosis development. To quantitatively estimate EGF mRNA expression in the liver during the course of cirrhosis development, mRNA levels of EGF were quantitatively evaluated by a real-time RT-PCR method. Intrahepatic mRNA levels of EGF were increased gradually and significantly higher in rats treated with DMN for 4 weeks than in normal controls. However, intrahepatic mRNA levels of EGF were then decreased markedly and significantly lower in rats treated with DMN for 6 weeks than both in normal controls, and in 2- and 4-week-treated ones. Each bar represents the mean \pm SD of 5 animals. $* 0.01<\mathrm{p}<0.05$

were significantly higher than those of normal controls. However, intrahepatic mRNA levels of EGF were decreased markedly in rats treated with DMN for 6 weeks. Levels of EGF expression in the liver were significantly lower in rats treated with DMN for 6 weeks than in both normal, and 2and 4-week-treated ones.

Intrahepatic expression of TGF- $\beta 1$ during the course of cirrhosis development. We then examined the intrahepatic expression of TGF- $\beta 1$ in rats treated with DMN. TGF- $\beta 1$ 


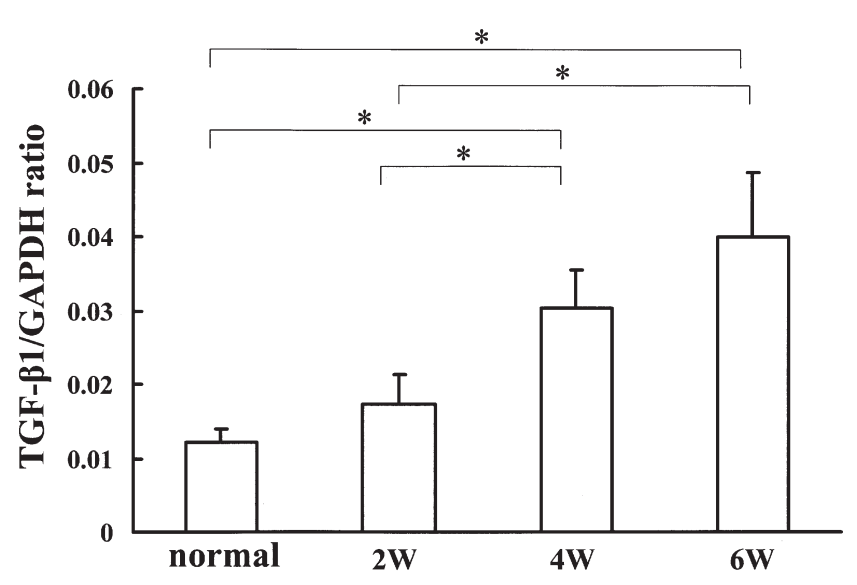

Figure 7. Intrahepatic mRNA expression of TGF- 11 in the course of cirrhosis development. To assess expression levels of TGF- $\beta 1$ in the liver during the course of cirrhosis development, mRNA levels of TGF- 31 were quantitatively evaluated by a real-time RT-PCR method. Intrahepatic mRNA levels of TGF- $B 1$ were increased gradually according to the period of DMN treatment. Intrahepatic expression levels of TGF- $\beta 1$ were significantly higher in rats treated with DMN for 6 weeks than in normal and 2-week-treated ones. Intrahepatic TGF- $\$ 1$ expression was also higher in 6-week-treated rats than in 4-week-treated ones, although the differences were not statistically significant. Each bar represents the mean \pm SD of 5 animals. ${ }^{*} 0.001<\mathrm{p}<0.01$.

expression in the liver was increased gradually according to the period of DMN treatment (Fig. 7). Intrahepatic mRNA levels of TGF- 31 of rats treated with DMN for 4 weeks were significantly higher than those of normal and 2-week-treated ones. Intrahepatic mRNA levels of TGF- 11 were further increased in rats treated with DMN for 6 weeks. Levels of TGF- $\$ 1$ expression in the liver were significantly higher in rats treated with DMN for 6 weeks than in normal and 2-weektreated ones. Intrahepatic TGF- $B 1$ expression reached a peak at the time of cirrhosis manifestation, although the values were not significantly different between 4- and 6-week-treated ones.

\section{Discussion}

The response to recurrent or continuous injury, in the liver and in other organs, is one of wound healing. The wounding process is characterized by a typical constellation of features such as increased production of extracellular matrix, secretion of various cytokines and growth factors, and proliferation of a unique population of cells known as myofibroblasts. In the liver, chronic injury causes continuous hepatocyte destruction and TGF- 31 stimulates quiescent HSCs into activated myofibroblast-like cells, which produce extracellular matrix to retrieve lost space made by destruction of hepatic parenchymal tissue. Hepatocytes have an enormous proliferative potential that can be unleashed under certain conditions (27-30). Nevertheless, there is evidence that the proliferative activity of hepatocytes diminishes in advanced liver cirrhosis in humans and in chronic injury in mice, reaching a state of replicative senescence $(31,32)$.

PCNA is a stable cell cycle-related nuclear protein, $36 \mathrm{kDa}$ in molecular weight, which is increasingly expressed in late G1 and throughout $\mathrm{S}$ phase of the cell cycle. Its rate of synthesis is correlated with the proliferative rate of cells $(33,34)$. Several studies comparing PCNA immunohisto- chemistry with established proliferation markers indicate that immunostaining of PCNA can be used to define and map proliferating cells in animal and human tissues and that this method represents a reliable marker for the determination of proliferative activity $(35,36)$. By using a PCNA immunostaining method, we previously showed that in a DMN-induced rat cirrhosis model, hepatocytes exhibited marked proliferation in response to chronic hepatic damage. However, at the time of cirrhosis manifestation, the proliferative capability of hepatocytes were severely impaired and returned to the normal levels before DMN treatment, in which hepatocytes are in a non-proliferative quiescent stage $(5,9)$. In the present study we employed a real-time RT-PCR method to evaluate intrahepatic mRNA expression levels of PCNA during the course of cirrhosis development. Consistent with our previous report with PCNA immunostaining $(5,9)$, intrahepatic PCNA expression was increased according to the period of DMN treatment, but it was reduced significantly at the time of cirrhosis manifestation and comparable to that in normal liver. These results indicate that although hepatocytes can proliferate in response to hepatic damage for certain time periods, the proliferative capability of hepatocytes is exhausted during continuously lasting hepatic damage. This exhaustion of the proliferative capability of hepatocytes is considered to be a main cause of the development of liver cirrhosis. Accordingly, the next important issue to be examined is why hepatocytes lose the proliferative capability during the development of liver cirrhosis.

EGF is believed to be one of the most important mitogens for hepatocytes. Therefore, it is considered that disruption of the regulation of the EGF system is contributed to the development of liver cirrhosis. However, little is known about disproportion of EGF during the development of liver cirrhosis. It had previously been reported that standard Northern blot analyses were not sensitive enough to detect an EGF signal with mRNA isolated from cirrhotic rat livers $(18,37)$. Therefore, in the present study, we employed a much more sensitive analysis by means of quantitative real-time RT-PCR method. We sequentially assessed intrahepatic expression levels of EGF during the course of cirrhosis development. Intrahepatic mRNA levels of EGF were increased in response to chronic liver injury induced by DMN. There was a tendency that EGF expression was elevated as an increase of collagen fiber accumulation in the liver. However, EGF expression in the liver was then markedly decreased at the time of cirrhosis manifestation and significantly lower compared with normal liver. Bissig et al (38) have also reported similar experimental results. They produced liver cirrhosis in rats by using a bile duct-ligated model. In their experiments, all bile ductligated animals had cirrhosis 25 days after surgery as assessed by macroscopic and microscopic inspection. The investigators examined the levels of intrahepatic EGF mRNA expression by a competitive RT-PCR method, and demonstrated that the liver homogenate of bile duct-ligated rats contained approximately $30 \%$ of EGF mRNA compared with that of unligated control animals.

EGF exerts the ability of hepatocyte proliferation through its receptor, and EGF/EGF receptor signaling activates a specific group of signal transducers and activators of transcription $(39,40)$. Kömüves et al (41) evaluated EGF and 
EGF receptor expression in surgically resected human liver specimens, by employing biotinylated antisense oligonucleotide probes to localize hepatic mRNA transcripts in situ. They have shown that EGF transcription was extremely low in control normal livers, but was highly elevated and localized to regenerative hepatic nodules in cirrhotic livers. In contrast, EGF receptor mRNA transcripts were expressed constitutively. Therefore, it was suggested that expression levels of EGF but not EGF receptor was responsible for the proliferative capability of hepatocytes. We have shown in the present study that the intrahepatic expression of EGF was increased significantly in response to chronic liver injury. However, intrahepatic EGF production ability is probably exhausted because of overloaded production. This could contribute to the loss of parenchymal liver tissue observed in cirrhosis.

TGF- $\beta 1$ is believed to be a key molecule that activates HSCs, resulting in production of collagen fibers (42-44). Abundant evidence points mechanistically to a critical role for HSCs in the pathogenesis of hepatic fibrosis. A central feature of the fibrogenic response is the transformation of HSCs from quiescent to an activated state (21). TGF- 31 appears to be the most profibrogenic cytokine present in the liver $(45,46)$. When TGF- $\$ 1$ was overexpressed in the liver, it led to fibrosis (47), and when inhibited during experimental liver injury, fibrosis was decreased (48). TGF-ß1 appears to act via direct stimulation of extracellular matrix production in HSCs. A number of other cytokines and peptides appear to exhibit profibrogenic properties toward HSCs; however, none is as potent as TGF- 31 . In the present study, we have shown that the intrahepatic expression of TGF- $\beta 1$ was increased gradually according to an increase of intrahepatic extracellular matrix, and levels of intrahepatic mRNA transcripts reached a peak at the time of cirrhosis manifestation.

In conclusion, during the course of cirrhosis development, hepatocytes revealed high proliferative capability in response to hepatocyte damage. However, according to the period of continuous hepatic damage, hepatocytes gradually lost their proliferative capability due, in part, to significant reduction of EGF expression. Furthermore, the intrahepatic expression of TGF- $\beta 1$ was increased gradually according to the period of chronic liver injury, which was considered to induce the activation of HSCs and production of extracellular matrix. Therefore, strategies to maintain sufficient levels of intrahepatic EGF expression and reduce enhanced intrahepatic TGF- $\beta 1$ expression may be effective in inhibiting the development of liver cirrhosis.

\section{References}

1. Kita Y, Masaki T, Funakoshi F, Yoshida S, Tanaka M, Kurokohchi K, Uchida N, Watanabe S, Matsumoto K and Kuriyama S: Expression of G1 phase-related cell cycle molecules in naturally developing hepatocellular carcinoma of Long-Evans Cinnamon rats. Int J Oncol 24: 1205-1211, 2004.

2. Masaki T, Shiratori Y, Rengifo W, Igarashi K, Yamagata M, Kurokohchi K, Uchida N, Miyauchi Y, Yoshiji H, Watanabe S, Omata $\mathrm{M}$ and Kuriyama S: Cyclins and cyclin-dependent kinases: comparative study of hepatocellular carcinoma versus cirrhosis. Hepatology 37: 534-543, 2003.

3. Masaki T, Morishita A, Nakai S, Uchida N, Kurokohchi K, Watanabe S and Kuriyama S: Cell cycle of hepatocellular carcinoma. In: New Perspectives in Cancer Research and Therapy. Kuriyama S and Yoshiji H (eds). Research Signpost, Kerala, pp183-190, 2005.
4. Morishita A, Masaki T, Yoshiji H, Nakai S, Ogi T, Miyauchi Y, Yoshida S, Funaki T, Uchida N, Kita Y, Funakoshi F, Usuki H, Okada S, Izuishi K, Watanabe S, Kurokohchi K and Kuriyama S: Reduced expression of cell cycle regulator p18 $18^{\mathrm{INK} 4 \mathrm{C}}$ in human hepatocellular carcinoma. Hepatology 40: 677-686, 2004.

5. Funakoshi F, Masaki T, Kita Y, Hitomi M, Kurokohchi K, Uchida N, Watanabe S, Yoshiji H and Kuriyama S: Proliferative capability of hepatocytes and expression of G1-related cell cycle molecules in the development of liver cirrhosis in rats. Int J Mol Med 13: 779-787, 2004

6. Yuji J, Masaki T, Yoshida S, Kita Y, Feng H, Uchida N, Yoshiji H, Kitanaka A, Watanabe S, Kurokohchi K and Kuriyama S: Identification of p46 Shc expressed in the nuclei of hepatocytes with high proliferating activity: study of regenerating rat liver. Int J Mol Med 13: 721-728, 2004.

7. Yoshida S, Masaki T, Feng H, Yuji J, Miyauchi Y, Funaki T, Yoshiji H, Matsumoto K, Uchida N, Watanabe S, Kurokohchi K and Kuriyama S: Enhanced expression of adaptor molecule of p46 Shc in nuclei of hepatocellular carcinoma cells: study of LEC rats. Int J Oncol 25: 1089-1096, 2004.

8. Masaki T, Tokuda M, Yoshida S, Nakai S, Morishita A, Uchida N, Funaki T, Kita Y, Funakoshi F, Nonomura T, Himoto T, Deguchi A, Kimura Y, Izuishi K, Wakabayashi H, Usuki H, Yoshiji H, Watanabe S, Kurokohchi K and Kuriyama S: Comparison study of the expressions of myristoylated alaninerich $\mathrm{C}$ kinase substrate in hepatocellular carcinoma, liver cirrhosis, chronic hepatitis, and normal liver. Int J Oncol 26: 661-671, 2005.

9. Inoue H, Yokoyama F, Kita Y, Yoshiji H, Tsujimoto T, Deguchi A, Nakai S, Morishita A, Himoto T, Kimura Y, Uchida N, Masaki T, Watanabe S and Kuriyama S: Relationship between the proliferative capability of hepatocytes, and the intrahepatic expression of hepatocyte growth factor and c-Met in the course of rat cirrhosis development. Int J Mol Med 17: 857-864, 2006.

10. Marti U, Burwen SJ and Jones AL: Biological effects of epidermal growth factor, with emphasis on the gastrointestinal tract and liver: an update. Hepatology 9: 126-138, 1989.

11. Marti U, Burwen SJ, Barker ME, Huling S, Feren AM and Jones AL: Effect of oxidative iodination of epidermal growth factor on its binding and secretion by hepatocytes. J Cell Biochem 40: 109-119, 1989 .

12. Marti U, Burwen SJ, Wells A, Barker ME, Huling S, Feren AM and Jones AL: Localization of epidermal growth factor receptor in hepatocyte nuclei. Hepatology 13: 15-20, 1991.

13. Gruppuso PA, Mead JE and Fausto N: Transforming growth factor receptors in liver regeneration following partial hepatectomy in the rat. Cancer Res 50: 1464-1469, 1990.

14. Noguchi S, Ohba Y and Oka T: Influence of epidermal growth factor on liver regeneration after partial hepatectomy in mice. J Endocrinol 128: 425-431, 1991.

15. Jones DE Jr, Tran-Patterson R, Cui DM, Davin D, Estell KP and Miller DM: Epidermal growth factor secreted from the salivary gland is necessary for liver regeneration. Am J Physiol 268: G872-G878, 1995.

16. Richman RA, Claus TH, Pilkis SJ and Friedman DL: Hormonal stimulation of DNA synthesis in primary cultures of adult rat hepatocytes. Proc Natl Acad Sci USA 73: 3589-3593, 1976.

17. St. Hilaire RJ, Hradek GT and Jones AL: Hepatic sequestration and biliary secretion of epidermal growth factor: evidence for a high-capacity uptake system. Proc Natl Acad Sci USA 80: 3797-3801, 1983.

18. Müllhaupt B, Feren A, Fodor E and Jones A: Liver expression of epidermal growth factor RNA. Rapid increases in immediateearly phase of liver regeneration. J Biol Chem 269: 19667-19670, 1994.

19. Marra F: Chemokines in liver inflammation and fibrosis. Front Biosci 7: D1899-D1914, 2002.

20. Gressner AM, Weiskirchen R, Breitkopf K and Dooley S: Roles of TGF-B in hepatic fibrosis. Front Biosci 7: D793-D807, 2002.

21. Friedman SL, Maher JJ and Bissell DM: Mechanisms and therapy of hepatic fibrosis: report of the AASLD Single Topic Basic Research Conference. Hepatology 32: 1403-1408, 2000.

22. Bissell DM, Wang SS, Jarnagin WR and Roll FJ: Cell-specific expression of transforming growth factor- $\beta$ in rat liver. Evidence for autocrine regulation of hepatocyte proliferation. J Clin Invest 96: 447-455, 1995.

23. Yasuda H, Imai E, Shiota A, Fujise N, Morinaga T and Higashio K: Antifibrogenic effect of a deletion variant of hepatocyte growth factor on liver fibrosis in rats. Hepatology 24: 636-642, 1996. 
24. Baroni GS, D'Ambrosio L, Curto P, Casini A, Mancini R, Jezequel AM and Benedetti A: Interferon gamma decreases hepatic stellate cell activation and extracellular matrix deposition in rat liver fibrosis. Hepatology 23: 1189-1199, 1996.

25. Ueno T, Sujaku K, Tamaki S, Ogata R, Kin M, Nakamura T, Sakamoto M, Torimura T, Mitsuyama K, Sakisaka S, Sata M and Tanikawa K: OK-432 treatment increases matrix metalloproteinase-9 production and improves dimethylnitrosamineinduced liver cirrhosis in rats. Int J Mol Med 3: 497-503, 1999.

26. Kuriyama S, Tsujimoto T, Nakatani Y, Tsujinoue H, Yoshiji H, Mitoro A, Yamazaki M, Okuda H, Toyokawa Y, Nagao S, Nishiwaki I and Fukui H: Sonographic estimation of liver tumor development induced by oral administration of thioacetamide in rat. In Vivo 13: 129-134, 1999.

27. Wu JC, Merlino G and Fausto N: Establishment and characterization of differentiated, nontransformed hepatocyte cell lines derived from mice transgenic for transforming growth factor alpha. Proc Natl Acad Sci USA 91: 674-678, 1994.

28. Rhim JA, Sandgren EP, Degen JL, Palmiter RD and Brinster RL: Replacement of diseased mouse liver by hepatic cell transplantation. Science 263: 1149-1152, 1994.

29. Overturf K, Al-Dhalimy M, Ou CN, Finegold M and Grompe M: Serial transplantation reveals the stem-cell-like regenerative potential of adult mouse hepatocytes. Am J Pathol 151: 1273-1280, 1997.

30. Weglarz TC, Degen JL and Sandgren EP: Hepatocyte transplantation into diseased mouse liver. Kinetics of parenchymal repopulation and identification of the proliferative capacity of tetraploid and octaploid hepatocytes. Am J Pathol 157: 1963-1974, 2000.

31. Paradis V, Youssef N, Dargere D, Ba N, Bonvoust F, Deschatrette $\mathrm{J}$ and Bedossa P: Replicative senescence in normal liver, chronic hepatitis $\mathrm{C}$, and hepatocellular carcinomas. Hum Pathol 32: 327-332, 2001.

32. Falkowski O, An HJ, Ianus IA, Chiriboga L, Yee H, West AB and Theise ND: Regeneration of hepatocyte 'buds' in cirrhosis from intrabiliary stem cells. J Hepatol 39: 357-364, 2003.

33. Mathews MB, Bernstein RM, Franza BR Jr and Garrels JI: Identity of the proliferating cell nuclear antigen and cyclin. Nature 309: 374-376, 1984.

34. Prelich G, Tan CK, Kostura M, Mathews MB, So AG, Downey KM and Stillman B: Functional identity of proliferating cell nuclear antigen and a DNA polymerase-delta auxiliary protein. Nature 326: 517-520, 1987

35. Wolf HK and Michalopoulos GK: Hepatocyte regeneration in acute fulminant and nonfulminant hepatitis: a study of proliferating cell nuclear antigen expression. Hepatology 15: 707-713, 1992.
36. Rudi J, Waldherr R, Raedsch R and Kommerell B: Hepatocyte proliferation in primary biliary cirrhosis as assessed by proliferating cell nuclear antigen and Ki-67 antigen labelling. J Hepatol 22: 43-49, 1995.

37. Rall LB, Scott J, Bell GI, Crawford RJ, Penschow JD, Niall HD and Coghlan JP: Mouse prepro-epidermal growth factor synthesis by the kidney and other tissues. Nature 313: 228-231, 1985.

38. Bissig KD, Marti U, Solioz M, Forestier M, Zimmermann H, Luthi $\mathrm{M}$ and Reichen J: Epidermal growth factor is decreased in liver of rats with biliary cirrhosis but does not act as paracrine growth factor immediately after hepatectomy. J Hepatol 33: 275-281, 2000.

39. Ruff-Jamison S, Chen K and Cohen S: Induction by EGF and interferon-gamma of tyrosine phosphorylated DNA binding proteins in mouse liver nuclei. Science 261: 1733-1736, 1993.

40. Ruff-Jamison S, Zhong Z, Wen Z, Chen K, Darnell JE Jr and Cohen S: Epidermal growth factor and lipopolysaccharide activate Stat 3 transcription factor in mouse liver. J Biol Chem 269: 21933-21935, 1994.

41. Kömüves LG, Feren A, Jones AL and Fodor E: Expression of epidermal growth factor and its receptor in cirrhotic liver disease. J Histochem Cytochem 48: 821-830, 2000.

42. Lotersztajn S, Julien B, Teixeira-Clerc F, Grenard P and Mallat A: Hepatic fibrosis: molecular mechanisms and drug targets. Annu Rev Pharmacol Toxicol 45: 605-628, 2005.

43. Fausto N: Liver regeneration and repair: hepatocytes, progenitor cells, and stem cells. Hepatology 39: 1477-1487, 2004.

44. Bataller R and Brenner DA: Liver fibrosis. J Clin Invest 115 : 209-218, 2005.

45. Hellerbrand C, Stefanovic B, Giordano F, Burchardt ER and Brenner DA: The role of TGFß1 in initiating hepatic stellate cell activation in vivo. J Hepatol 30: 77-87, 1999.

46. Schnabl B, Kweon YO, Frederick JP, Wang XF, Rippe RA and Brenner DA: The role of Smad3 in mediating mouse hepatic stellate cell activation. Hepatology 34: 89-100, 2001.

47. Sanderson N, Factor V, Nagy P, Kopp J, Kondaiah P, Wakefield L, Roberts AB, Sporn MB and Thorgeirsson SS: Hepatic expression of mature transforming growth factor $B 1$ in transgenic mice results in multiple tissue lesions. Proc Natl Acad Sci USA 92: 2572-2576, 1995.

48. George J, Roulot D, Koteliansky VE and Bissell DM: In vivo inhibition of rat stellate cell activation by soluble transforming growth factor B type II receptor: a potential new therapy for hepatic fibrosis. Proc Natl Acad Sci USA 96: 12719-12724, 1999. 